\title{
Pattern of Skin Disease among University Students in Marrakesh
}

\author{
Najat Elaattoul ${ }^{1 *}$, Kenza Kandri Rody ${ }^{1}$, Ouafa Hocar ${ }^{1}$, Said Amal ${ }^{1}$
}

\author{
${ }^{1}$ Dermatology and venereology department of Mohammed VI University hospital center, Marrakesh, Morocco \\ DOI: $10.36347 /$ sasjm.2021.v07i03.011 \\ | Received: 02.03.2021 | Accepted: 19.03.2021 | Published: 30.03.2021 \\ *Corresponding author: Najat Elaattoul
}

Abstract

Original Research Article

Skin diseases are a common problem among young adults. They can result in serious emotional and psychological disorders. This study was conducted to assess the frequency of dermatologic diseases among Moroccan university students living on the public university campus. 460 individuals were included accounting for $14,8 \%$ of the university campus students. The mean age was 21 years old. $44 \%$ were males and $56 \%$ females. All dermatological diseases were recorded. The inflammatory dermatoses were the most prevalent $(38 \%)$ with predominance of acne (17\%), followed by contact eczema (9\%), psoriasis $(7 \%)$, urticaria (4\%) and rosacea $(2 \%)$. Infectious dermatoses were found in $32 \%$ of cases, with epidermomycosis on top of the list (16\%), then scabies $(10 \%)$ and genital infections in $6 \%$ of cases. Hair pathology was reported in $25 \%$ of students, mostly represented by hair loss and dandruff. No case of malignant disease has been reported. The average development time was 11 months, in $70 \%$ of cases after settling in the university campus. A low socio-economic level was noted in $68 \%$ of the students. $80 \%$ of cases affirmed that the dermatologic disorder negatively impacted their quality of life. Our results highlight the high morbidity of skin diseases in this population, thus more researches should be carried out in this specific community in order to improve their conditions and reduce the burden of dermatologic disorders.

Keywords: University campus, students, pattern, dermatological diseases, acne.

Copyright ( 2021 The Author(s): This is an open-access article distributed under the terms of the Creative Commons Attribution 4.0 International License (CC BY-NC 4.0) which permits unrestricted use, distribution, and reproduction in any medium for non-commercial use provided the original author and source are credited.

\section{INTRODUCTION}

Dermatologic disorders affect a large number of people and are associated with a heavy burden of disease worldwide as they can threaten patient's wellbeing, mental health, ability to function, and social participation [1, 2]. Skin diseases are more common among young adult's particularly cosmetic problems [3]. In addition, they are known to be common in places where society lives in a crowded area such as dormitories [4]. Unfortunately, there is a lack of data about skin diseases among university students living on campus.

Our work aimed to assess the pattern of dermatologic diseases among Moroccan university students living on the public university campus in Marrakesh.

\section{MATERIAL AND METHODS}

This is a cross-sectional study conducted on May 2019 in the university campus of Marrakech after taking the ethical approval from institutional ethics committee. Among the 3100 student living on the campus, only 460 consulted for dermatologic disorders and consented to participate in the study. Demographic data was collected including age, gender and socioeconomic level. The past medical history and duration of symptoms were noted and all the patients underwent physical screening. Additionally, each participant determined whether the skin problem affected or not the quality of life. Clinical photographs were taken.

\section{RESULTS}

We included 460 individuals in the study accounting for $14,8 \%$ of the campus university students. The mean age was 21,2 years old. $56 \%$ were females and $44 \%$ males.

The average duration of symptoms was 11 months, for the majority (70\% of cases) after settling in the university campus. Only 60 individuals (13\%) had previously consulted for the dermatologic disorder and $68 \%$ of students declared a low socio-economic level.

Of all the recorded skin diseases [table 1], the inflammatory dermatoses were the most prevalent accounting for $37,8 \%$ (174 cases), with a predominance of acne noted in $16,9 \%$ of cases. The other 
inflammatory dermatoses were contact eczema in $8,9 \%$ of cases, psoriasis in $6,9 \%$ of cases, urticaria in $4,1 \%$ of cases and rosacea in $1 \%$ of cases.

Infectious dermatoses were seen in $34,3 \%$ of cases, with epidermomycosis on top of the list (16\% of cases) including onychomycosis, pityriasis versicolor and dermatophytoses of glabrous skin. Scabies infection was found in $10 \%$ of cases followed by genital infections in $6,1 \%$ of cases.

Hair pathology was reported in $25 \%$ of students mostly represented by hair loss $(13,3 \%)$ and dandruff $(6,3 \%)$. While skin pigmentation disorders accounted for $2 \%$.
Two cases of vitiligo and one case of hirsutism were recorded. No case of malignant disease was reported. Among all the participants, $80 \%$ of cases affirmed that the dermatologic disorder negatively impacted their quality of life, particularly female students $(55 \%)$.

Students diagnosed with chronic dermatological conditions were referred to dermatological consultation center of the Mohammed VI university hospital for further investigations and continuous follow up.

Table-1: spectrum of dermatologic disorders in the study population

\begin{tabular}{|c|c|}
\hline Disease & $\%$ \\
\hline Inflammatory dermatoses & $\mathbf{3 7 , 8 \%}$ \\
\hline - Acne & $16,9 \%$ \\
\hline - $\quad$ Eczema & $8,9 \%$ \\
\hline - $\quad$ Psoriasis & $6,9 \%$ \\
\hline - Urticaria & $4,1 \%$ \\
\hline - $\quad$ Rosacea & $1 \%$ \\
\hline Infectious dermatoses & $34,1 \%$ \\
\hline - Onychomycosis & $3 \%$ \\
\hline - $\quad$ Pityriasis versicolor & $9 \%$ \\
\hline - $\quad$ Dermatophytoses of glabrous skin & $4 \%$ \\
\hline - $\quad$ Scabies & $10 \%$ \\
\hline - $\quad$ Genital infection & $6,1 \%$ \\
\hline - $\quad$ Viral warts & $1 \%$ \\
\hline - $\quad$ Cutaneaous Herpes & $1 \%$ \\
\hline Hair pathology & $25 \%$ \\
\hline - Hair loss & $13,3 \%$ \\
\hline - $\quad$ Dandruff & $6,3 \%$ \\
\hline - $\quad$ Androgenitic alopecia & $5 \%$ \\
\hline - $\quad$ Alopecia areata & $0,4 \%$ \\
\hline Pigmentation disorder & $2,1 \%$ \\
\hline Others & $1 \%$ \\
\hline Malignant disease & $\mathbf{0 \%}$ \\
\hline
\end{tabular}

\section{DISCUSSION}

Skin disorders have been recognized as the $4^{\text {th }}$ leading cause of nonfatal disease burden in 2010 and 2013 [2], they are a major health problem in developing countries [5]. Their development may be the result of several factors like genetic, gender, race, socioeconomic status, nutrition, personal habits and age [3]. Therefore, the pattern of skin diseases varies between countries and even within regions [5].

Skin diseases are usually associated with a low mortality rate, but they may negatively influence individual's social life, daily activities, and psychological state [6]; especially among young people who have an increased awareness of their body image and beauty [3]. A Chinese study showed that depression, anxiety and sleep disturbance were more common in patients with skin diseases compared with healthy controls among university students [1]. In our study, a negative impact on quality of life was found in $80 \%$ of cases.

Prevention of disfigurement and psychological sequelae of skin morbidities requires a proper management at earlier stages along with education of students [3].Unfortunately, the state of health of the university students is poorly studied and researches in this area remain rare. Our results highlight the high morbidity of skin diseases in these population particularly inflammatory dermatoses.

Acne was the most frequent disorder as reported in other studies [3, 7, 8, 9]. This could be linked to the young age of the students, as acne is 
generally considered a disease of the adolescence [10]. Moreover, hot weather and sun exposure are found to play a significant role in acne [11] which is compatible with Marrakesh hot climate.

The other inflammatory dermatoses were eczema, psoriasis and urticaria. Their frequency can be explained by increased emotional stress during college studies, which has been associated to the onset and exacerbation of these skin diseases $[12,13]$.

Hair loss was the second complaint after acne accounting for $13,3 \%$. We could incriminate poor and bad nutrition habits resulting in iron deficiency, stress and poor hair care.

Infectious dermatoses were the next most common problem, especially epidermomycosis and scabies. They are probably consequent to the poor hygienic conditions and hot humid environments which are created by overcrowding. Previous studies showed high percentages of fungal and parasitic infections among students living in dormitories [3, 4, 14]. This was the direct reflect of a low socio-economic level, characterizing $68 \%$ of cases in our study. In fact, socioeconomic factors contribute greatly to the epidemiology of skin disease and high household density is especially associated with transmissible skin disease [2]. Therefore, we took advantage of consultation during our study, to improve student's awareness about importance of personal and collective hygiene measures.

\section{CONCLUSION}

The state of health of the campus university students is poorly studied. Observational studies should open the door to further researches in this specific population in order to improve their conditions. Despite the benignity of the skin diseases found, the establishment of a regular medical consultation and the strengthening of hygiene measures could help reduce this morbidity.

\section{REFERENCES}

1. Shen M, Xiao Y, Su J, Zhao S, Li J, Tao J, Kang X, Wu B, Shan S, Wang X, Chen X. Prevalence and patient-reported outcomes of noncommunicable skin diseases among college students in China. JAAD International. 2020 Jul 1;1(1):23-30.

2. Seth D, Cheldize K, Brown D, Freeman EE. Global burden of skin disease: inequities and innovations. Current dermatology reports. 2017 Sep;6(3):20410.
3. Joseph N, Kumar GS, Nelliyanil M. Skin diseases and conditions among students of a medical college in southern India. Indian dermatology online journal. 2014 Jan;5(1):19.

4. Sahala MA, Soedarman S, Rizky LA. The Prevalence of Skin Diseases and its Association with Hygiene Behavior and Level of Education in a Pesantren, Jakarta Selatan 2013. eJournal Kedokteran Indonesia. 2016;4(2).

5. Hoq AJMS, Sultana F, Abedin MJ, Matiur Rahman GM. Pattern of Skin Diseases among Medical Students: A Study in Cumilla Medical College, Cumilla, Bangladesh. American Journal of Dermatology and Venereology. 2020; 9(4): 5154

6. Sahala MA, Soedarman S, Rizky LA, Natanegara AP, Advani MS, Sungkar S. The prevalence of skin diseases and its association with hygiene behavior and level of education in a Pesantren, Jakarta Selatan 2013. eJournal Kedokteran Indonesia. 2016 Sep 19:119-24.

7. Noorbala MT, Kafaie P. Pattern of skin diseases in the Central Iran, Yazd Province. J Pak Assoc Dermatol. 2010;20: 137-141.

8. Roodsari RM, Malekzad F, Amini R, Shiri M. Frequency of skin disorders among university students in Shahid Beheshti University of Medical Sciences. Pajouhesh Dar Pezeshkir. 2006;30:1836.

9. Ertam I, Babur Y, Unal I,Alper S. The frequency of skin diseases among students in a university clinic. Skinmed. 2010, 8(5):261-263.

10. Oyedepo JT, Katibi OS, Adedoyin OT. Cutaneous disorders of adolescence among Nigerian secondary school students. Pan Afr Med J. 2020; 36: 36 .

11. Dreno B, Shourick J, Kerob D, Bouloc A, Taïeb C. The role of exposome in acne: results from an international patient survey. Journal of the European Academy of Dermatology and Venereology. 2020;34(5):1057-1064.

12. Labadie M S, Kent G G, Gawkrodger D J. The relationship between stress and the onset and exacerbation of psoriasis and other skin conditions. British Journal of Dermatology. 1994;130(2): 199203.

13. Egan K G, Morano M A. Prevalence of Stress References on College Freshmen Facebook Profiles. Comput Inform Nurs. 2011; 29(10): 586592.

14. Tabasi M, mizarei A, Javadinia S A, Eskandarion M R, Amrollahi H. Prevalence of superficial and cutaneous fungal infections among dormitory students of Semnan University of Medical Sciences. Koomesh. 2016; 17(3):747-751. 